\title{
[gw22-e0724] THE PREVALENCE AND PROGNOSTIC VALUE OF LIVER FUNCTION ABNORMALITIES IN PATIENTS WITH CHRONIC SYSTOLIC HEART FAILURE
}

Yu Shengbo Renmin Hospital of Wuhan University

\subsection{6/heartjnl-2011-300867.631}

Background The prevalence and prognostic value of liver function abnormalities in patients with chronic systolic heart failure (HF) have not been systematically evaluated.

Methods and results 16681 in-hospital patients from 12 hospital of Hubei province, China, with diagnosis of chronic systolic HF and LVEF $<50 \%$ were enrolled. All patients were followed up by telephone contact. Patients were divided into death and survival groups according to the result of follow-up. Over media 3 years follow-up, 6453 (38.69\%) patients died. The prevalence of liver function abnormality was 71.94\% (12001/16681). The elevations of direct bilirubin, $\gamma$-glutamyl- transferase and alanine aminotransferase were the most common which accounts 33.37\% (4863/14574), 32.51\% (4337/13341) and $30.12 \%$ (5024/16681), respectively. The abnormality of alkaline phosphatase was less, the elevation and declination of which accounts $3.82 \%(474 / 12397)$ and $4.51 \%$ (559/12397) respectively. The prevalence of low albumin and total bilirubin elevation was $23.24 \%$ (3408/14664) and 19.37\% (3231/16681). Low albumin (HR 0.411, 95\% CI 0.225 to $0.752 ; \mathrm{p}=0.004$ ) and elevated direct bilirubin (HR 1.785, 95\% CI 1.625 to 1.986; $\mathrm{p}=0.037$ ), total bilirubin (HR 1.358, 95\% CI 1.034 to 1.783 ; $\mathrm{p}=0.028$ ) were determinated as the independent risk factors of total mortality. Study revealed correlations of LVEF with direct bilirubin ( $\mathrm{r}=$ $-0.235, \mathrm{p}<0.0001)$, total bilirubin $(\mathrm{r}=-0.209, \mathrm{p}<0.0001)$, albumin $(r=0.107, p<0.0001)$ and right ventricular end-diastolic diameter (RVDD) with direct bilirubin $(\mathrm{r}=0.149, \mathrm{p}<0.0001)$, total bilirubin $(\mathrm{r}=0.154, \mathrm{p}<0.0001)$, albumin $(\mathrm{r}=-0.086, \mathrm{p}<0.0001)$. 